\title{
A Near Infrared Fluorescent Probe for Sensitive Determination of Human Serum Albumin
}

\author{
Xiaodan ZENG, ${ }^{*}$ Mingshuo MA,* Baocun ZHU, ${ }^{* * \dagger}$ and Lin ZHU***† \\ *Center of Analysis and Measurement, Jilin Institute of Chemical Technology, Jilin 132022, \\ People's Republic of China \\ **School of Resources and Environment, University of Jinan, Jinan 250022, People's Republic of China \\ ***School of Chemical and Pharmaceutical Engineering, Jilin Institute of Chemical Technology, Jilin 132022, \\ People's Republic of China
}

\begin{abstract}
A fluorescent probe $\mathbf{1}$ has been successfully developed to determine human serum albumin (HSA). Probe $\mathbf{1}$ expresses a dramatic fluorescence enhancement to HSA without interference from other amino acids. Under the optimal conditions, the calibration graphs are linear over the range of $0-13.3 \mu \mathrm{g} / \mathrm{mL}$ with the limit of determination of $0.61 \mu \mathrm{g} / \mathrm{mL}$. Thus, this probe shows high sensitivity and selectivity to HSA.
\end{abstract}

Keywords Human serum albumin, fluorescence, determination

(Received March 4, 2016; Accepted August 2, 2016; Published December 10, 2016)

\section{Introduction}

Human serum albumin (HSA) is the most abundant plasma protein that is produced in the liver. ${ }^{1-3}$ It plays a crucial role in maintaining the osmotic pressure of the blood compartment, transporting hormones, binding fatty acid and buffering blood $\mathrm{pH}^{4}{ }^{4}$ The concentration of serum albumin in body fluids is almost considered a reliable sign of health. The normal concentration of HSA in serum is in the range of $35-55 \mathrm{~g} / \mathrm{L}$ and is approximately $30 \mathrm{mg} / \mathrm{L}$ in urine. ${ }^{5}$ If an excess amount of HSA is present in the urine, it may be the early sign of cardiovascular disease or kidney disease in diabetes mellitus and hypertension. Meanwhile, if the amount of HSA is too low, it could be related to the liver cirrhosis, liver failure or chronic hepatitis. ${ }^{6}$ So, it is vital to develop an accurate method with high selectivity and a low detection limit for clinical use.

Several methods have been used to determine HSA content, including visible absorption (UV-vis) spectroscopy, ${ }^{7}$ electrochemical, ${ }^{8}$ capillary electrophoresis ${ }^{9}$ and light scattering. ${ }^{10}$ While, several problems, especially the specific problem of assay, may occur and influence the estimation of HSA.

The development of a fluorescent technique is extremely significant because of its simplicity for real time assessment without the need for advanced or complicated instruments and rapid signal without destructive interference. ${ }^{11,12}$ Various reagents including dyes, ${ }^{13}$ polymers ${ }^{14}$ and gold nanoparticles ${ }^{15}$ have been used as HSA sensors. Although several fluorescent probes have been reported, it was found that they had low excitation $(<500 \mathrm{~nm})$ and emission wavelengths $(<600 \mathrm{~nm})$, which may not prevent the interference from the biological autofluorescence. ${ }^{16,17}$

$\dagger$ To whom correspondence should be addressed.

E-mail: 1cyzbc@163.com (B. Z.); jiangzxd@163.com (L. Z.)
In view of the limitations of reported probes and the significance of HSA in clinical diagnoses, we focused on the design and synthesis of a probe that can show fluorescence in the NIR region.

To achieve this target, we designed and synthesized a novel near infrared fluorescent probe $(\mathbf{1}$, Scheme 1$)$ for the detection of HSA. Probe $\mathbf{1}$ is a derivative of 2-dicyanomethylene-3cyano-4,5,5-trimethyl-2,5-dihydrofuran (TCF), which is an important dye for its long emission wavelength $(>600 \mathrm{~nm})$ and has attracted much attention. ${ }^{18-20}$ This fluorescent probe (1) was developed for detecting HSA by non-covalent bonding. Its fluorescence behavior can be governed by double bonds, and it can sense HSA by a fluorescent turn-on response for the inhibition of its fluorescent behavior through the hydrophobic domain of HSA. This probe contains a conjugated $\pi$-electron system and it will lose its fluorescence by non-radiative pathway for its double bonds. When it interacts with HSA, the double bond behavior will be blocked and it stabilizes itself by adapting to planar geometry and will show an intensive fluorescence signal.

It exhibited specific fluorescence enhancement to HSA without any interference from metal ions and other amino acids. This probe has the advantages of: (1) the working principle between 1 and HSA is non-covalent bonding, which can not alter the native protein structure; (2) shows a long-wavelength

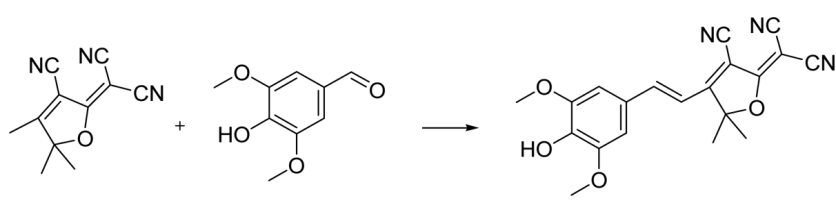

Scheme 1 Synthesis of $\mathbf{1}$. 


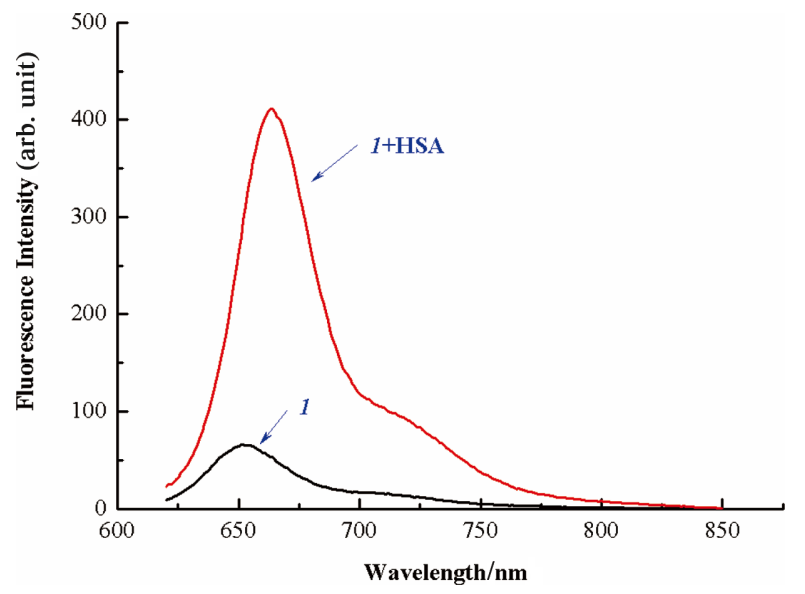

Fig. 1 The fluorescence spectra of $\mathbf{1}(10 \mu \mathrm{M})$ in the absence and presence of $130 \mu \mathrm{g} / \mathrm{mL}$ HSA in a mixture of Tris $(10 \mathrm{mM}, \mathrm{pH} 7.4)$ and ethanol $(95: 5, \mathrm{v} / \mathrm{v})$ when excited at $600 \mathrm{~nm}$.

emission $\left(\lambda_{\mathrm{em}}=660 \mathrm{~nm}\right)$, which may prevent interferences that come from the biological autofluorescence; and (3) shows high sensitivity (the detection limit of $0.61 \mu \mathrm{g} / \mathrm{mL}$ ) and high selectivity to HSA.

\section{Experimental}

\section{Reagents and chemicals}

Human serum albumin was purchased from Sigma. All solvents used were of analytical grade without further purification. Solutions of different cations were prepared by separately dissolving $10.0 \mathrm{mM}$ of each cation in distilled water. Sodium salts were dissolved in distilled water $(5 \mathrm{mM})$. All amino acids were dissolved in distilled water $(5 \mathrm{mM})$.

\section{Apparatus}

${ }^{1} \mathrm{H}$ NMR and ${ }^{13} \mathrm{C}$ NMR spectra were taken on a Bruker AMX400 spectrometer (Bruker, German). Chemical shifts $(\delta)$ were reported in ppm relative to a $\mathrm{Me}_{4} \mathrm{Si}$ standard in $\mathrm{CDCl}_{3}$. Electrospray ionization (ESI) mass spectra were measured with an LC-MS 2010A (Shimadzu, Japan) instrument.

All fluorescence spectra were carried out on a Cary eclipse fluorescence spectrofluorometer (Varian, USA) with $1.0 \mathrm{~cm}$ quartz cell. The fluorescence spectra were recorded in the range of $620-800 \mathrm{~nm}$ with excitation wavelength at $600 \mathrm{~nm}$. The excitation and emission slit is $10 \mathrm{~nm}$. The final concentration of 1 was $10 \mu \mathrm{M}$ and the concentration of HSA was between 0 and $13.3 \mu \mathrm{g} / \mathrm{mL}$ in a mixture of Tris $(10 \mathrm{mM}, \mathrm{pH} 7.4)$ and ethanol $(95: 5, \mathrm{v} / \mathrm{v})$.

\section{Synthetic procedures}

First, 2-dicyanomethylene-3cyano-4,5,5-trimethyl-2,5-dihydrofuran (199 mg, $1 \mathrm{mmol}$ ), 4-hydroxy-3,5-dimethoxybenzaldehyde (273 $\mathrm{mg}, 1.5 \mathrm{mmol}$ ) and piperidine as catalyst were dissolved in $10 \mathrm{~mL}$ absolute ethanol. The mixture was stirred at room temperature and monitored by TLC. Then the crude product was purified by silica column chromatography (the eluent is $\left.\mathrm{CH}_{2} \mathrm{Cl}_{2}: \mathrm{CH}_{3} \mathrm{OH}=80: 1, \mathrm{v} / \mathrm{v}\right)$ to obtain the pure probe. ${ }^{1} \mathrm{H} \mathrm{NMR}$ $\left(400 \mathrm{MHz}, \mathrm{DMSO}-d_{6}\right) \delta\left(\times 10^{-6}\right): 1.70(\mathrm{~s}, 6 \mathrm{H}), 3.79(\mathrm{~s}, 6 \mathrm{H}), 6.67$ (d, $J=7.2 \mathrm{~Hz}, 1 \mathrm{H}), 7.04(\mathrm{~s}, 2 \mathrm{H}), 7.69(\mathrm{~d}, J=7.2 \mathrm{~Hz}, 1 \mathrm{H})$. ${ }^{13} \mathrm{C}$ NMR (100 MHz, DMSO- $\left.d_{6}\right) \delta\left(\times 10^{-6}\right): 19.03,26.60,43.15$, 56.23, 56.49, 96.58, 107.72, 108.74, 114.11, 115.55, 123.57,

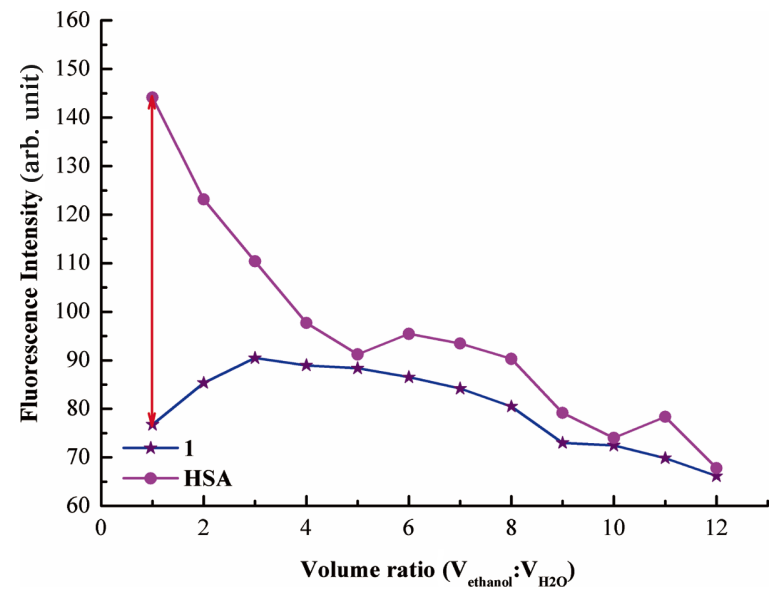

Fig. 2 The fluorescence intensity spectra of $1(10 \mu \mathrm{M})$ in water with different proportion of ethanol (v/v). 1, 0.5:9.5;2, 1:9;3, 2:8; 4, $2.5: 7.5 ; 5,3: 7 ; 6,3.5: 6.5 ; 7,4: 6 ; 8,5: 5 ; 9,6: 4 ; 10,7: 3 ; 11,8: 2 ; 12,9: 1$.

144.86, 150.28, 176.89. ESI-MS calcd. for $\mathrm{C}_{20} \mathrm{H}_{16} \mathrm{~N}_{3} \mathrm{O}_{4}[\mathrm{M}-\mathrm{H}]^{-}$ 362.1 , found 362.1 .

\section{Results and Discussion}

\section{Spectra characteristics of 1-HSA}

The HSA-sensing performance of $\mathbf{1}$ was examined in Tris- $\mathrm{HCl}$ buffer solution. The coordination of $\mathbf{1}$ with HSA caused the increase of fluorescence intensity of $\mathbf{1}$ (Fig. 1). 1 was weakfluorescent itself when excited at $600 \mathrm{~nm}$, while the emission intensity at $660 \mathrm{~nm}$ increased with the addition of HSA to the solution. When the amount of HSA reached $130 \mu \mathrm{g} / \mathrm{mL}$, a 4.3-fold fluorescence enhancement was obtained and the fluorescence intensity was found to show an excellent relation with the amount of HSA. We believe that the fluorescence enhancement of probe $\mathbf{1}$ with the addition of HSA is due to increased hydrophobic interaction. Hence, this sensing system yields an optical signal change. These results indicate that $\mathbf{1}$ could be used as a new fluorescence probe for the determination of HSA, and the present method was able to detect HSA in a fluorescence enhancement manner.

\section{Effect of polarity of solution}

The probe consisted of a strong "pull-push" system, therefore it may be sensitive to external environment change. To find out whether 1 and HSA were affected by the polarity of the solution, the fluorescence behavior of $\mathbf{1}$ and HSA in different waterethanol ratios was studied. As seen from Fig. 2, 1 and HSA showed polarity sensitivity in different proportions ethanol in water. The maximum relative fluorescence intensity occurred when the ratio was 5:95. So we selected the ratio of 5:95 as the suitable system in this assay.

\section{Precision, sensitivity and working curve}

The calibration graph for HSA under the optimum conditions is shown in Fig. 3. The fluorescence intensity of probe $\mathbf{1}$ produced satisfactory linearity with the increase in the concentration of HSA. The relationship between the fluorescence intensity and HSA content was linear over the range of $0-13.3 \mu \mathrm{g} / \mathrm{mL}(R=0.9959)$. As depicted by the scheme, such fluorescence enhancement might be attributed to hydrophobic interaction between 1 and HSA. 


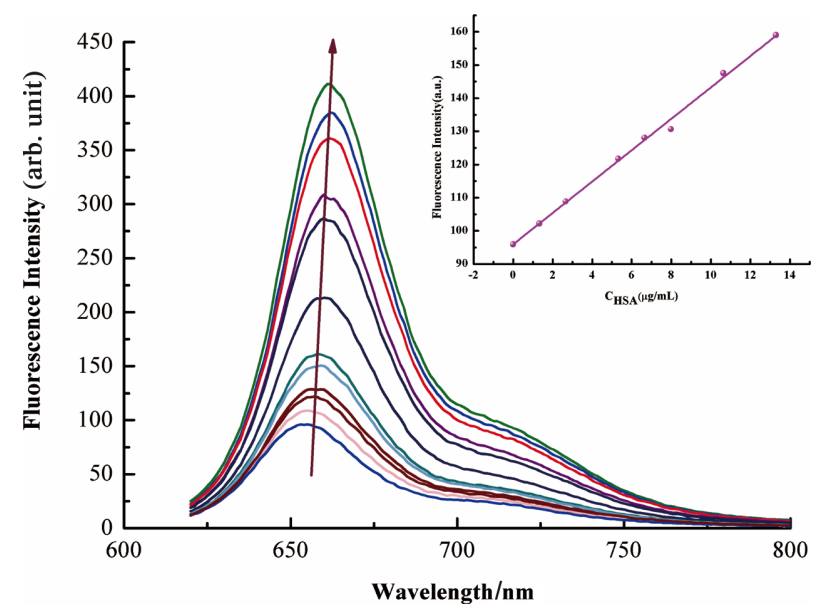

Fig. 3 Fluorescence emission spectra of $\mathbf{1}(10 \mu \mathrm{M})$ upon addition of increasing concentrations of HSA $(0-130 \mu \mathrm{g} / \mathrm{mL})$ in a mixture of Tris $(10 \mathrm{mM}, \mathrm{pH} 7.4)$ and ethanol $(95: 5, \mathrm{v} / \mathrm{v})$.

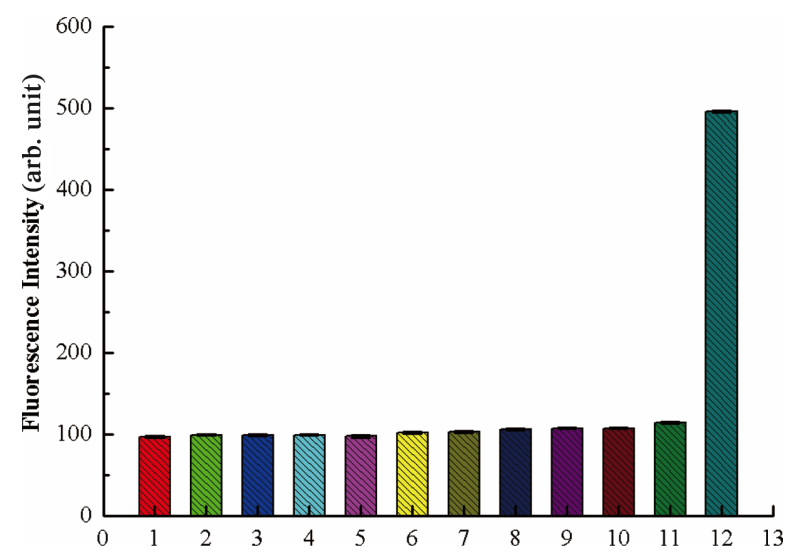

Fig. 4 Fluorescence responses of $\mathbf{1}(10 \mu \mathrm{M})$ to HSA and various cations $(10 \mu \mathrm{M})$ at $660 \mathrm{~nm}$ in a mixture of Tris $(10 \mathrm{mM}, \mathrm{pH} 7.4)$ and ethanol (95:5, v/v). 1, Blank; $2, \mathrm{Na}^{+} ; 3, \mathrm{~K}^{+} ; 4, \mathrm{Mg}^{2+} ; 5, \mathrm{Cu}^{2+} ; 6, \mathrm{Zn}^{2+} ; 7$, $\mathrm{Ni}^{2+} ; 8, \mathrm{Hg}^{2+} ; 9, \mathrm{Mn}^{2+} ; 10, \mathrm{Fe}^{3+} ; 11, \mathrm{Al}^{3+} ; 12$, HSA (three times for each experiment).

The limit of detection (LOD) is defined corresponding to the lowest concentration of the analyzed material that can be detected but can not be quantified necessarily. The detection limit was calculated by using detection limit $=3 \sigma / k$, which yielded the LOD value of $0.61 \mu \mathrm{g} / \mathrm{mL}$ that is sufficiently low for monitoring the HSA level in biological samples. In the detection limit, $\sigma$ is the standard deviation of the blank measurement and $k$ is the slope between the fluorescence intensity versus HSA concentration. The result shows high detection sensitivity for HSA.

\section{Selectivity/specificity}

We studied the molecular recognition behavior of $\mathbf{1}$ toward different analytes including common ions and amino acids. Figures 4, 5 and 6 show that no clear fluorescence change appears when common ions and amino acids were added into the solution of $\mathbf{1}$. So, all amino acids and metal ions failed to produce any discernible spectral change under the same conditions. The results indicated that the probe $\mathbf{1}$ can selectively detect HSA among the various proteins and common ions.

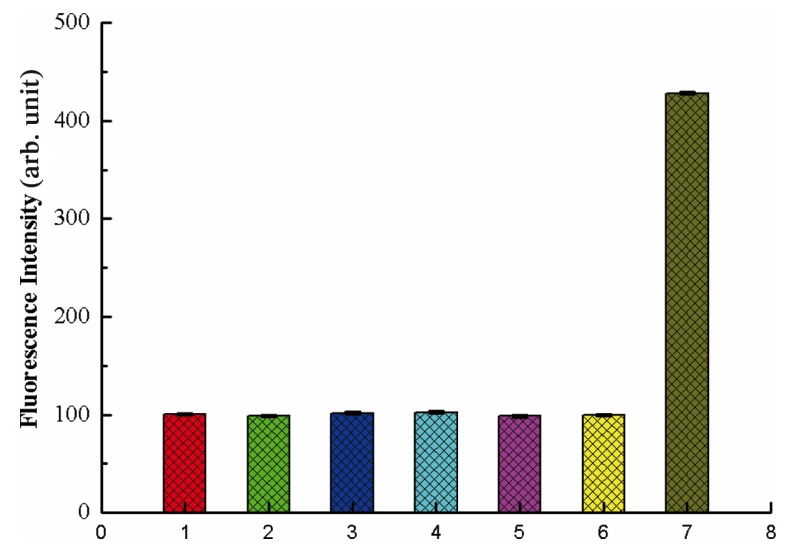

Fig. 5 Fluorescence responses of $\mathbf{1}(10 \mu \mathrm{M})$ to HSA and various anions $(10 \mu \mathrm{M})$ at $660 \mathrm{~nm}$ in a mixture of Tris $(10 \mathrm{mM}, \mathrm{pH} 7.4)$ and ethanol (95:5, v/v). 1, Blank; 2, $\mathrm{Cl}^{-} ; 3, \mathrm{Ac}^{-} ; 4, \mathrm{SO}_{4}{ }^{2-} ; 5, \mathrm{ClO}_{4}^{-} ; 6$, $\mathrm{NO}_{3}^{-} ; 7$, HSA (three times for each experiment).

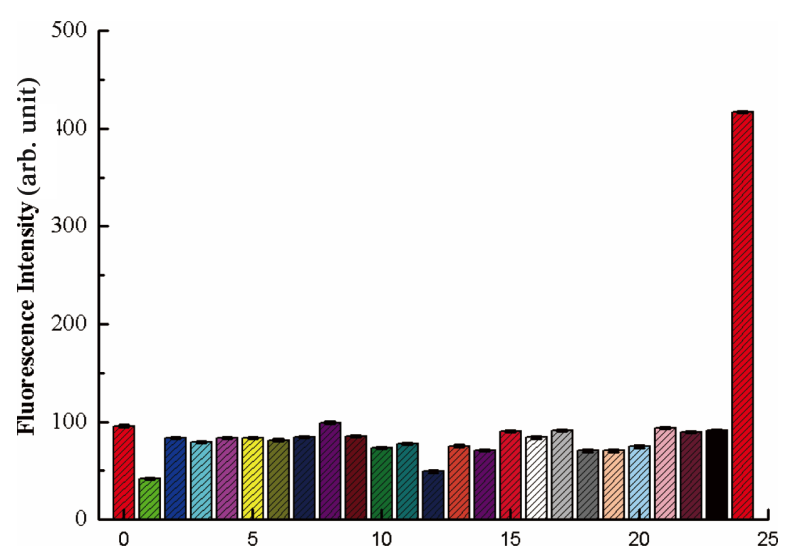

Fig. 6 Fluorescence responses of $\mathbf{1}(10 \mu \mathrm{M})$ to HSA and various amino acids $(10 \mu \mathrm{M})$ at $660 \mathrm{~nm}$ in a mixture of Tris $(10 \mathrm{mM}, \mathrm{pH} 7.4)$ and ethanol (95:5, v/v). 0, Blank; 1, Ala; 2, Ser; 3, Glu; 4, Lys; 5, Thr; 6, Leu; 7, Val; 8, Phe; 9, Met; 10, Asp; 11, Trp; 12, Arg; 13, Tyr; 14, His; 15, Ile; 16, Cys; 17, Lys; 18, GSH; 19, Gly; 20, Pro; 21, Gln; 22, IgG; 23, transferring; 24, HSA (three times for each experiment).

From these studies, it may be concluded that probe $\mathbf{1}$ can act as an efficient fluorescent probe for HSA.

\section{Interference test}

To better investigate the selectivity of this probe, the interference of various foreign substances was tested. The detection behavior of this probe towards HSA with the addition of different amino acids and metal ions was also investigated by fluorescence spectroscopy to further evaluate the selectivity, and the results are shown in Fig. 7. The results showed that the interference of these materials is very weak. These results further demonstrated that other meterials do not markedly interfere with detection of HSA. So this probe can be used to determine HSA with high selectivity and without major interference.

In summary, HSA concentrations can be determined in an accurate and specific manner without interference of any common ions and amino acids. It can be concluded from these feats that this method may have practical use. 


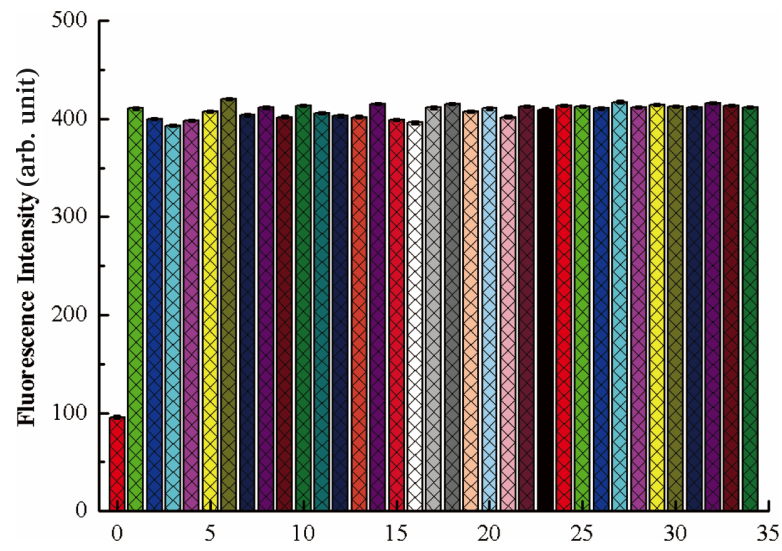

Fig. 7 Fluorescence responses of $\mathbf{1}(10 \mu \mathrm{M})$ to HSA in the presence of different cations $(10 \mu \mathrm{M})$ and amino acids $(10 \mu \mathrm{M})$ at $660 \mathrm{~nm}$ in a mixture of Tris (10 mM, pH 7.4) and ethanol (95:5, v/v). 0, Blank; 1 , Ala; 2, Ser; 3, Glu; 4, Lys; 5, Thr; 6, Leu; 7, Val; 8, Phe; 9, Met; 10, Asp; 11, Trp; 12, Arg; 13, Tyr; 14, His; 15, Ile; 16, Cys; 17, Lys; 18, GSH; 19, Gly; 20, Pro; 21, Gln; 22, IgG; 23, transferring; $24, \mathrm{Na}^{+} ; 25$, $\mathrm{K}^{+} ; 26, \mathrm{Mg}^{2+} ; 27, \mathrm{Cu}^{2+} ; 28, \mathrm{Zn}^{2+} ; 29, \mathrm{Ni}^{2+} ; 30, \mathrm{Hg}^{2+} ; 31, \mathrm{Mn}^{2+} ; 32, \mathrm{Fe}^{3+}$; $33, \mathrm{Al}^{3+} ; 34$, HSA (three times for each experiment).

Table 1 Accuracy of the fluorescent method for HSA determination

\begin{tabular}{ccccc}
\hline $\begin{array}{c}\text { Human serum } \\
\text { sample }\end{array}$ & $\begin{array}{c}\text { The clinical data/ } \\
\mathrm{mg} \mathrm{mL}^{-1}\end{array}$ & $\begin{array}{c}\text { This method/ } \\
\mathrm{mg} \mathrm{mL}^{-1}\end{array}$ & $\begin{array}{c}\text { Recovery, } \\
\%\end{array}$ & RSD \\
\hline 1 & 21.8 & 17.1 & 78.4 & 1.91 \\
2 & 23.7 & 19.5 & 82.3 & 1.20 \\
3 & 35.6 & 27.7 & 77.8 & 1.39 \\
\hline
\end{tabular}

\section{Recovery}

The present method was applied to detecting HSA in human serum samples. Human serum samples were stored at $0-5^{\circ} \mathrm{C}$ and diluted appropriately to be within the linear range of determination of HSA. The HSA levels were estimated from the fluorescence intensity values using the calibration graph. Table 1 summarizes the results, which are close to the clinical data that got from a hospital. Therefore, this probe can be used to determine HSA for its reliability, sensitivity and practice.

\section{Conclusions}

In summary, a new fluorescent probe $\mathbf{1}$ for detection of HSA was reported. It showed excellent sensing properties for HSA. It expressed an obvious fluorescence enhancement with HSA in emission spectra and without interference from different ions and other biomolecules commonly present in the environment or biosystems. This probe can detect trace amount of HSA and is expected to show promise further applications in chemical and medical research.

\section{Acknowledgements}

We gratefully acknowledge financial support from the National Nature Science Foundation of China (No. 21107029), Outstanding Young Scientists Award Fund of Shandong Province (BS2013HZ007), Postdoctoral Science Foundation of China (2013M541953), and Educational Commission of Jilin Province of China $(2014344,2014351)$. We also thank our colleagues and other students who participated in this work.

\section{References}

1. S. N. Cao, B. S. Liu, Z. Y. Li, and B. H. Chong, J. Lumin., 2014, 145, 94.

2. M. Cieplak, K. Szwabinska, M. Sosnowska, B. K. C. Chandra, P. Borowicz, K. Noworyta, F. D'Souza, and W. Kutner, Biosens. Bioelectron., 2015, 74, 960.

3. C. Boiero, D. Allemandi, M. Longhi, and J. M. Llabot, J. Pharm. Biomed. Anal., 2015, 111, 186.

4. K. Borowczyk, M. Wyszczelska-Rokiel, P. Kubalczyk, and R. Głowacki, J. Chromatogr. B, 2015, 57, 981 .

5. V. J. Alino and K. L. Yang, Analyst, 2011, 136, 3307.

6. S. H. Murch, P. J. D. Winyard, S. Koletzko, B. Wehner, H. A. Cheema, R. A. Risdon, A. D. Phillips, N. Meadows, N. J. Klein, and J. A. Walker-Smith, Lancet, 1996, 347, 1299.

7. D. J. Kosman, R. Hassett, D. S. Yuan, and C. J. Mc, J. Am. Chem. Soc., 1998, 120, 4037.

8. H. M. Zhang, Z. W. Zhu, and N. Q. Li, Fresenius' J. Anal. Chem., 1999, 363, 408.

9. I. H. Lee, D. Pinto, E. A. Arriaga, Z. Zhang, and N. J. Dovichi, Anal. Chem., 1998, 70, 4546.

10. G. Yao, K. A. Li, and S. Y. Tong, Anal. Lett., 1998, 31, 1689.

11. N. Kishikawa, K. Ohyama, A. Saiki, A. Matsuo, M. F. B. Ali, M. Wada, K. Nakashima, and N. Kuroda, Anal. Chim. Acta, 2013, 780, 1.

12. W. Shu, L. G. Yan, Z. K. Wang, J. Liu, S. Zhang, C. Y. Liu, and B. C. Zhu, Sens. Actuators, B, 2015, 221, 1130.

13. M. L. Silber and B. B. Davitt, J. Biochim. Biophys. Acta, 2000, 1480, 321.

14. M. H. Lan, J. S. Wu, W. M. Liu, W. J. Zhang, J. C. Ge, H. Y. Zhang, J. Y. Sun, W. W. Zhao, and P. F. Wang, J. Am. Chem. Soc., 2012, 134, 6685.

15. X. R. He, H. B. Liu, Y. L. Li, S. Wang, Y. J. Li, N. Wang, J. C. Xiao, X. H. Xu, and D. B. Zhu, Adv. Mater., 2005, 17, 2811.

16. X. X. Hu, Y. T. Su, Y. W. Ma, X. Q. Zhan, H. Zheng, and Y. B. Jiang, Chem. Commun., 2015, 51, 15118.

17. H. L. Chen, X. F. Bao, F. Li, B. J. Zhou, R. L. Ye, and J. Zhu, RSC Adv., 2015, 5, 85095.

18. B. Zhu, H. Kan, J. Liu, H. Liu, Q. Wei, and B. Du, Biosens. Bioelectron., 2014, 52, 298.

19. B. Zhu, W. Wang, L. Liu, H. Jiang, B. Du, and Q. Wei, Sens. Actuators, B, 2014, 191, 605.

20. L. Feng, Z. M. Liu, L. Xu, X. Lv, J. Ning, and J. Hou, Chem. Commun., 2014, 50, 14519. 